\title{
História econômica de Forquilhinha (1895-2011): de núcleo colonial a município
}

History of economic Forquilhinha (1895-2011): from colonial village to county

Histoire économique de Forquilhinha (1895-2011): colony pour la municipalité

Historia de los derechos económicos forquilhinha (1895-2011): a ciudad colonial núcleo

\author{
João Henrique Zanelatto* \\ (jhz@unesc.net) \\ Paulo Sérgio Osório* \\ (pso@unesc.net)
}

Recebido em 03/02/2014; revisado e aprovado em 14/07/2014; aceito em 10/11/2014

DOI: http://dx.doi.org/10.1590/151870122015210

\begin{abstract}
Resumo: O escrito objetivou historicizar o processo de desenvolvimento das atividades econômicas do município de Forquilhinha, situado no Sul Catarinense e, ao mesmo tempo, fazer uma periodização do seu desenvolvimento econômico. Abordou-se a história econômica de Forquilhinha a partir de quatro momentos: 1) 1895-1929: Comércio nas Vendas; 2) 1929-1959: Das dificuldades econômicas a criação da Sociedade União Colonial; 3) 1959-1989: O crescimento da indústria em Forquilhinha; 4) 1989-2011: A emancipação e a integração socioeconômica de Forquilhinha.

Palavras-chave: História Econômica. Forquilhinha. Periodização.

Abstract: The writing process aimed to historicize the development of economic activities in the municipality of Forquilhinha located in southern Santa Catarina and, at the same time, sought to make a timeline of its economic development. Addressed the economic history of Forquilhinha from four periods: 1) 1895-1929: Trade in Sales, 2) 1929-1959: From the economic difficulties the creation of the Society Colonial Union, 3) 1959-1989: The growth of industry in Forquilhinha; 4) 1989-2011: The empowerment and socio-economic integration of Forquilhinha.

Key words: Economic History. Forquilhinha. Periodization.

Résumé: Le processus d'écriture visant à historiciser le développement des activités économiques dans la municipalité de Forquilhinha situé dans le sud de Santa Catarina et, dans le même temps, cherché à faire une chronologie de son développement économique. Consacrées à l'histoire économique de Forquilhinha de quatre périodes: 1) 1895-1929: le commerce des ventes, 2) 1929-1959: les difficultés économiques de la création de l’Union Colonial Society, 3) 1959-1989: La croissance de l'industrie dans Forquilhinha; 4) 1989-2011: L'intégration et l'autonomisation socio-économique des Forquilhinha.

Mots-clés: Histoire économique. Forquilhinha. Périodisation.

Resumen: El proceso de escritura destinado a historiar el desarrollo de las actividades económicas en el municipio de Forquilhinha situada en el sur de Santa Catarina y al mismo tiempo trató de hacer una cronología de su desarrollo económico. Se dirigió a la historia económica de Forquilhinha de cuatro períodos: 1) 1895-1929: Comercio en Venta, 2) 1929-1959: De las dificultades económicas de la creación de la Unión Colonial Society, 3) 1959-1989: El crecimiento de la industria en Forquilhinha; 4) 1989-2011: La integración y el empoderamiento socioeconómico de Forquilhinha. Palabras clave: Historia económica. Forquilhinha. Periodización.
\end{abstract}

\section{Introdução}

O município de Forquilhinha está situado no Sul Catarinense, a $200 \mathrm{KM}$ da capital Florianópolis, ocupado desde o final do século XIX por população constituída de alemães, italianos, luso-brasileiros, poloneses, russos, japoneses e afrodescendentes. Sua economia esteve assentada até o final dos anos de 1980 na agricultura. Mudanças foram se processando somente no final dos anos 80, quando conseguiu a emancipação política do município de Criciúma. Forquilhinha foi, desde o final do século XIX, um núcleo colonial constituído por uma diversidade de grupos étnicos, conseguiu elevar-se a condição de distrito em 1959 e, em 1989, veio à emancipação. Nesse longo período, experimentou mudanças em seu desenvolvimento econômico. Assim, o escrito objetivou historicizar o processo de desenvolvimento das atividades econômicas de Forquilhinha e, ao mesmo tempo, fazer uma periodização do seu desenvolvimento econômico. Abordou-se a história econômica de Forquilhinha a partir de quatro momentos: 1) 1895-1929: Comércio nas Vendas; 2) 19291959: Das dificuldades econômicas à criação da Sociedade União Colonial; 3) 1959-1989: O crescimento da indústria em Forquilhinha; 4) 1989-2011: A emancipação e a integração socioeconômica de Forquilhinha.

* Universidade do Extremo Sul Catarinense, Criciúma, Santa Catarina, Brasil. 


\section{Comércio nas vendas: 1895-1929}

O atual município de Forquilhinha, como já exposto, está situado no Sul Catarinense, teve sua base econômica fundamentalmente centrada nas atividades agrícolas até o final da década de 1980. Essa situação foi se alterando ao longo dos anos 80 , com um processo de crescimento da indústria, comércio e intensa urbanização. Desde o final do século XIX, já havia moradores nas terras que compreendem o atual município de Forquilhinha. Os índios que foram os primeiros habitantes e, aos poucos, foram sendo exterminados, os luso-brasileiros, italianos, poloneses, russos, alemães ${ }^{1}$, viviam nos primeiros anos de uma economia basicamente de subsistência. A distância dos centros urbanos, a deficiência de estradas e meios de transporte eram os obstáculos ao desenvolvimento (ZANELATTO; OSÓRIO, 2012).

Em relação ao comércio e à indústria nas terras de Forquilhinha no início do século XX, havia, na propriedade de Manoel João Rocha, um engenho de açúcar e outro de farinha de mandioca, neles trabalhavam vários colonos da região como agregados. Havia as bodegas José Manuel e do italiano Suppi. Víveres e utensílios eram comprados de viajantes que passavam vez por outra, o café e o sal grosso eram os artigos mais cobiçados, a moeda era muito escassa entre a população que habitava Forquilhinha. Em 1914, Frederico Oderdenge, que não era agricultor, abriu uma pequena "venda" próxima ao rio Mãe Luzia, esta foi vendida para Gabriel Arns em 1922².

\footnotetext{
${ }^{1}$ Outro aspecto que o escrito procurou contemplar foi dar visibilidade para os vários grupos étnicos que contribuíram no desenvolvimento econômico do município de Forquilhinha: luso-brasileiros, alemães, italianos, poloneses, russos, japoneses, afrodescendentes. Ao dar visibilidade para a diversidade étnica dos habitantes que compõem o município, divergiu-se de grande parte da historiografia e dos discursos que buscam construir uma identidade alemã para Forquilhinha.

${ }^{2}$ Sobre a venda e seu proprietário observaram-se algumas divergências nos livros de: TISCOSKI, Adolfo. Uma história de imigrantes. Curitiba, PR: Gráfica Vicentina, 1994, p. 20. BACK, Adolfo. 100 anos: história de Forquilhinha. Criciúma, SC: Ed. UNESC, 1995, p. 43. ARNS, Otília. Forquilhinha 1912-2002: história e resgate da memória dos nossos antepassados. Florianópolis, SC: IOESC, 2003, p. 240. Para Adolfo Tiscoski a venda foi vendida em 1914 e seu proprietário chamava-se
}

A primeira atafona e também o secador de arroz da região ficavam em Mãe Luzia, na propriedade do "russo" Seberg. Essa família de letões também se dedicava à criação de ovelhas. A lã era fiada num tear, para confecção de peças de vestuário tricotadas. (TISCOSKI, 1994, p. 18).

No início do século $X X$, próximo a Forquilhinha, estavam localizadas as duas principais casas comerciais da região, a dos irmãos Bortoluzzi, em Nova Veneza, e a de Giácomo Burigo, em Mãe Luzia. O senhor Olindo Scarduelli, morador de Morro Comprido, lembra que criavam porcos e levavam até Mãe Luzia "ali havia uma fábrica, levava porco nas carroças, alguns fugiam dava muito trabalho" (Olindo Scarduelli, entrevistado em 2011). O senhor Arnoldo Preis, ao falar das dificuldades dos colonos de Forquilhinha, assim se expressou:

Não sei como se ganhava uns tostões ou mil réis, porque não havia comércio, não havia indústrias. Plantava-se arroz, mas só para comer. Milho, não se vendia. Criavam-se porcos, animais e vacas. Nos nossos primeiros anos aqui porcos não eram vendidos, derretia-se a banha em casa. Vendia-se a banha enlatada. Havia os Bortoluzzi de Nova Veneza que compravam tudo que os colonos produziam. Tinham também descascador. Eram três irmãos com comércio bastante sortido. Depois colocaram em Mãe Luzia uma fábrica de banha de um Minatto e do Giácomo Búrigo. (DALL'ALBA, 1997, p. 363).

Outros colonos adquiriam alguns gêneros alimentícios, roupas e comercializavam a banha e os derivados do porco na venda da família Napoli em Meleiro. A banha era enlatada no estabelecimento da família Napoli e, em seguida, "transportada em carro de boi, até Maracajá. De lá seguia de trem até Laguna, onde era então embarcada com destino ao Rio de Janeiro" (TISCOSKI, 1994, p. 22).

Os colonos também transportavam principalmente arroz e banha em carros de boi até a estação da estrada de ferro Dona Tereza Cristina, localizada em Palmeiras, hoje Pindotiba. As dificuldades eram grandes

\footnotetext{
Frederico Oterding. Em Adolfo Back e Otilia Arns a venda foi vendida em 1922 e seu proprietário chamavase Frederico Oderdenge. Mesmo com essas divergências o que fica evidenciado é que os autores estão se referindo da mesma venda e seu proprietário.
} 
para fazer esse trajeto, pois as estradas eram esburacadas, cobertas de pedras ou áreas pantanosas de difícil passagem. Era muito comum encontrar carros quebrados ou atolados ao longo das estradas (BACK, 1995, p. 12-13).

O comércio era também realizado com a região Serrana e com os serranos que aqui passavam com seus produtos indo para Tubarão e Laguna. Compravam-se ou trocavam-se alguns produtos com os serranos, estes muitas vezes pernoitavam nos arredores de Forquilhinha. Os colonos de Forquilhinha subiam a serra e compravam porcos. Seu Fridolino Stainer diz que "comprava porcos da serra, tratava com batatas, engordava e vendia" (DAROS, 2009, p. 123).

Depois de comprar a casa de comércio de Frederico Oderdenge em 1922, Gabriel Arns, que até aquele momento vivia exclusivamente da agricultura, passou a desenvolver as atividades comerciais. Arns ampliou a casa de comércio e se tornou o principal comerciante comprando e vendendo produtos para os colonos residentes nas terras de Forquilhinha, em especial aos colonos alemães.

Além da casa comercial, Gabriel Arns construiu uma pequena fábrica de banha "comprava os suínos abatidos da colônia e das redondezas, exportando a banha e a carne para o Rio de Janeiro" (SILVA, 1998, p. 114). Em 1923, comprou um beneficiador de arroz e, em seguida, montou uma serraria e uma olaria para fabricar tijolos, todas movidas por máquina a vapor (locomóvel) importadas da Alemanha (BACK, 1995, p. 44).

Os negócios de Gabriel Arns prosperaram rapidamente e, em Sangão, comprou um terreno com uma atafona e uma serraria, que passaram a ser administradas por seu cunhado Alfredo Steiner. Instalou também uma ferraria em Forquilhinha para seu cunhado Jorge Steiner, que produzia foice, enxada, facão, ferraduras, machado, entre outros produtos que eram comercializados com os colonos (ARNS, 2003, p. 241).

Em Forquilhinha, Gabriel Arns construiu uma instalação de grande porte, uma casa com dois andares que tinha múltiplas funções. No primeiro andar, na parte de trás da casa, havia uma grande cozinha e um refeitório onde cerca de trinta a quarentas operários faziam suas refeições na época da safra do porco, e havia também uma sala de jantar onde os "viajantes caixeiros" faziam suas refeições. Na parte da frente, ficavam as repartições de secos e molhados com uma infinidade de produtos que abasteciam as famílias da comunidade. O escritório de contabilidade ficava ao lado e era administrado por seu cunhado Adolfo Back, professor no período matutino e contador da casa comercial no período vespertino (ZANELATTO; OSÓRIO, 2012).

$\mathrm{O}$ rápido crescimento dos empreendimentos de Gabriel Arns foi interrompido com a crise mundial de 1929, iniciada nos Estados Unidos e atingindo drasticamente a economia brasileira. Grande parte dos empreendimentos de Gabriel Arns dependia da venda de seus produtos para os grandes centros do país, Rio de janeiro e São Paulo, estados duramente castigados com a crise, pois tinham a economia centrada nas exportações de café para os Estados Unidos e países da Europa. Essa crise afetou a economia da colônia e, em especial, os negócios de Gabriel Arns (ZANELATTO; OSÓRIO, 2012).

Mas como entender essa crise? Com o término da Primeira Guerra Mundial (1914 1918), os países da Europa ficaram com sua capacidade produtiva bastante reduzida, cenário esse que possibilitou aos Estados Unidos tornar-se, ao mesmo tempo, maior credor e centro financeiro mundiais. A economia americana vivia um período de grande euforia provocada pelo grande crescimento de suas indústrias e comércio que, durante a guerra, produziam e vendiam para a Europa. No pós-guerra, o consumo interno e as exportações não cresceram no mesmo ritmo da produção, o mercado não conseguia absorver tudo o que era produzido, provocando a crise de superprodução. A oferta excessiva de mercadorias e a falta de consumidores desencadearam uma crise na economia mundial (HOBSBAWM, 1995).

Antes da crise mundial de 1929, os negócios de Gabriel Arns já haviam sido duramente afetados. No ano de 1925, os preços dos produtos coloniais, banha, carne salgada, arroz, feijão subiram significativamente; esses produtos produzidos na fábrica de banha, no descascador de arroz de Gabriel Arns ou comprados por ele dos colonos, eram transportados para o porto de Laguna e embarcados para o Rio de Janeiro e São Paulo, mas, 
com a alta dos preços, ficaram nos depósitos de Laguna sem navios para transportá-los. No ano seguinte, em 1926, os preços dos produtos tiveram um declínio violento, voltaram aos valores anteriores da grande alta de 1925, e esta queda de preços das mercadorias afetou drasticamente os negócios de Gabriel Arns, que pagou preços muito altos aos produtos comprados dos colonos de Forquilhinha e região. Além disso, muitos dos produtos estocados em Laguna acabaram perdendo sua validade de uso e foram jogados ao mar (ZANELATTO; OSÓRIO, 2012, p. 90).

Arnoldo Preis narrou assim o crescimento e a crise dos negócios de Gabriel Arns:

Finalmente saiu aqui em Forquilhinha também. Foi um primo meu, o Gabriel Arns, quem começou e em 1925 já tinha uma casa de comércio bastante forte. Aí já vendia o porco carneado, com carne ou sem carne. Ele é que dava o jeito de encaixotar a banha e a carne e levar em carro de boi até Criciúma. De Criciúma a Laguna de trem. Em Laguna ficava lá apodrecendo antes que chegasse um navio para levá-la ao Rio de Janeiro. Lá não deixavam desembarcar... O Gabriel quebrou com aquilo. Um ano que deu uma safra boa comprou muito e deu uma baixa nos preços. (DALL'ALBA, 1997, p. 364-365).

O crescimento e as dificuldades dos negócios de Gabriel Arns foram narrados também por Aluísio Hoepers

Quem começou com uma pequena casa comercial foi o Gabriel Arns e chegou a ter grande comércio. Tudo que o colono precisava ele mandava pedir. Tecido, ferragens, secos e molhados. Comprava os produtos dos colonos. Depois, houve um ano em que ele comprou muito feijão, e esse teve uma quebra muito grande no preço. Isso arrastou seu Gabriel para a falência. A divida grande dele era com os Hoepcke. (DALL'ALBA, 1997, p. 368).

Nas narrativas de Arnold Preis e de Aluísio Hoepers, ficou evidenciado que ao longo dos anos de 1920, Gabriel Arns foi o principal comerciante da comunidade de Forquilhinha, através de sua casa comercial e demais empreendimentos, funcionou como um intermediário entre os colonos e os centros urbanos do sul catarinense e sudeste do país. Comprava os gêneros agrícolas dos colonos e revendia nos centros urbanos, trazia os produtos industrializados em especial do Rio de
Janeiro e São Paulo e os vendia aos colonos de Forquilhinha ${ }^{3}$. Tornou-se o comerciante mais rico de Forquilhinha e um influente líder político na comunidade. Mesmo com a crise que levou à falência de vários de seus negócios, a partir de 1926, como expostos nas narrativas, ele continuou a influenciar na economia e na política de Forquilhinha durante várias décadas.

Assim, na primeira fase da história de Forquilhinha, que compreende o período da história brasileira conhecido como a Primeira República (1889 - 1930), a economia de Forquilhinha girou em torno das casas comerciais criadas na comunidade e nos arredores de Forquilhinha. Luso-brasileiros, italianos, russos, poloneses e alemães que viviam nas terras de Forquilhinha, vendiam sua produção agrícola nas casas comercias de Nova Veneza, Mãe Luzia, Meleiro ou no comércio de Gabriel Arns, situados na própria comunidade.

\section{Das dificuldades econômicas à criação da Sociedade União Colonial: 1929-1959}

Além da crise mundial de 1929, que afetou drasticamente a economia brasileira, no ano seguinte o país vivenciou o movimento armado conhecido na historiografia como revolução de 1930, que colocou Getúlio Vargas na condução da nação e afastou do poder a oligarquia cafeeira de São Paulo. Dois anos depois, em 1932, os paulistas através de um movimento conhecido como movimento constitucionalista tentaram voltar ao poder, mas foram derrotados pelas forças fieis a Vargas depois de três meses de conflito armado.

Esses acontecimentos contribuíram significativamente para afetar a economia dos moradores da comunidade de Forquilhinha e de todo o sul catarinense, pois a economia da região dependia e muito das exportações

\footnotetext{
${ }^{3}$ É importante destacar que a figura do comerciante (intermediários) esteve presente em vários núcleos coloniais de imigração europeia de Santa Catarina durante a Primeira República (1889 1930). Muitos funcionaram também com banqueiros, pegavam o dinheiro dos colonos e emprestavam para outros colonos e assim conseguiam capitais para investir em seus empreendimentos. Sobre isso ver: SOUTO, Américo A. da Costa. Evolução histórico-econômica de Santa Catarina: estudo das alterações estruturais (século XVII-1960). Florianópolis, SC: Centro de Assistência Gerencial de Santa Catarina (CEAG/SC), 1980.
} 
de seus produtos para o Rio de Janeiro e São Paulo.

As dificuldades econômicas experimentadas pelos moradores de Forquilhinha no início dos anos de 1930 levaram os lusobrasileiros, italianos, russos e poloneses a desenvolverem basicamente atividades de subsistência, exercer outras atividades, como por exemplo, o trabalho nas minas de carvão de Criciúma ou migrarem para outras cidades. À medida que a economia foi se recuperando, esses colonos foram novamente vendendo seus produtos nas casas comerciais da região.

No entanto alguns moradores de Forquilhinha, de descendência alemã, enfrentaram a crise criando uma cooperativa, a Sociedade União Colonial. O Padre Paul Linnartz foi fundamental para a criação da cooperativa; vindo da Alemanha, chegou a Forquilhinha em 1932, sendo muito bem recebido pelos moradores, pois até aquele momento não havia um padre na comunidade. Logo que chegou, o Padre procurou se inteirar da situação da comunidade e percebeu as dificuldades que seus moradores vinham enfrentando.

Em um relatório de 17 páginas enviado a Associação do Reino Católico de Alemães Estrangeiros (R. K. A.), em Berlim, relatava a situação dos moradores da comunidade enfatizando a necessidade de ajuda, e prontamente a Associação atendeu aos reclames do padre enviando reforço financeiro para Forquilhinha (ARNS, 2003, p. 185-186).

A partir da presença do Padre Paul Linnartz, foram crescendo as articulações de cunho legal para a criação da Sociedade União Colonial. Para a constituição da Sociedade, foi definido que cada sócio deveria contribuir com a quantia de dois contos de reis para a formação do capital social. No entanto somente um dos sócios pagou de imediato o valor estipulado, Joaquim Junkes, os demais não possuíam recursos para contribuir. Foi o Padre Linnartz que emprestou a quantia de dois mil marcos, que convertidos em moeda nacional correspondiam a 13.490 .00 réis (BACK, 1995, p. 45). Esse foi o capital inicial da Sociedade União Colonial que seria criada oficialmente em 14 de junho de 1935.

De acordo com os estatutos da Sociedade União Colonial, os associados eram obrigados a comprar todos os gêneros de uso pessoal e doméstico bem como vender os produtos da sua lavoura na Sociedade. Para o funcionamento da Sociedade, alugaram o "prédio de Gabriel Arns, a parte em que tinha instalada a casa de negócio, paióis, fábrica de banha etc." (BACK, 1995, p. 45). O aluguel ficou estipulado em $12 \%$ dos lucros obtidos pela Sociedade. "Inventariou-se o pequeno estoque que Gabriel Arns mantinha, que passava agora para a Sociedade União Colonial" (BACK, 1995, p. 45). Esses dados são reveladores da difícil situação em que se encontravam os negócios de Gabriel Arns, que, ao que tudo indica, não havia conseguido se recuperar da crise do final da década de 1920.

No final do ano de 1935, após seis meses de funcionamento, a Sociedade União Colonial apresentou um lucro de $10.286 .300 \mathrm{mil}$ réis. Era o sucesso da sociedade que passou a ter grande importância no desenvolvimento da comunidade de Forquilhinha, em especial entre os descendentes de imigrantes alemães. A Sociedade União Colonial, por um bom tempo veio a substituir as casas de comércio particulares de Forquilhinha.

No período de sua existência, a Sociedade União Colonial atuou em várias frentes: em 1936, construiu uma nova fábrica de banha; em 1937, comprou de Gabriel Arns os prédios e terreno que até então eram alugados; também em 1937 era iniciada a fábrica de laticínios na antiga fábrica de banha, ali era produzido o queijo, intitulado com a marca SUCO. Era comercializado principalmente no Rio Grande do Sul. Em 1942, foi construída uma nova fábrica de queijo em conformidade com as exigências da inspetoria. Em 1947, a Sociedade conseguiu com a Companhia Telefônica Catarinense a instalação de um telefone no escritório, isso depois de a Sociedade ter colocado posteamento de Mãe Luzia até a ponte do Rio Sangão. Em 1948, adquiriu um caminhão, e outro, em 1956, os quais eram utilizados para entregar e buscar produto dos colonos. Em 1954, foi comprado o beneficiador de arroz, a atafona com terreno e prédios do senhor Fridolino Michels. Além dessas atividades, a Sociedade União Colonial comprou terrenos em Forquilhinha, fábrica de queijo em Braço do Norte e, em convênio com o governo do estado, construiu-se uma estação de monte e uma pocilga (BACK, 1995, p. 46-48).

A Sociedade funcionou ao longo de sua existência como uma cooperativa onde 
os sócios entregavam sua produção que era pesada e registrada em um livro caixa. Os sócios recebiam "o crédito que lhes permitia adquirir gêneros de suas necessidades, como sal, café, peças de tecidos, utensílios de cozinha, ferramentas e tudo mais" (TISCOSKI, 1994, p. 50). Não recebiam dinheiro pela sua produção e, quando não estavam precisando de algum produto, recebiam vales em papel que posteriormente foram substituídos por fichas de metal. "Isso por um lado dava certa garantia aos associados, mas por outro mantinha o sócio preso a um sistema monopolizado em que os interesses estariam voltados à Sociedade União Colonial" (MACHADO, 2004, p. 24). No estatuto da Sociedade União Colonial (1935), em seu artigo 47 parágrafo 2, determinava a cada sócio o direito de comprar e vender fora da Sociedade, mas somente com a permissão do diretor gerente. A Sociedade também fazia negócios com os não associados, "mas neste caso o negócio era sempre em dinheiro e a vista" (TISCOSKI, 1994, p. 500).

Como já exposto, a sociedade União Colonial foi formada por descendentes de alemães, seus sócios eram na sua ampla maioria de origem alemã. Diante desse dado, é imperativo fazer alguns questionamentos: Onde os colonos luso-brasileiros, italianos, poloneses e russos que moravam em Forquilhinha nas diversas comunidades, como por exemplo, Sanga do Engenho, Sanga do Café, São Roque, Morro Comprido, Pique Rio do Cedro, São Pedro, Taquaras, Barra da Sanga, comercializavam seus produtos nas décadas de 1930, 40 e 50 ? Havia nessas comunidades bodegas, vendas, armazéns? Os colonos levavam sua produção para outras praças, Meleiro, Maracajá, Nova Veneza, Mãe Luzia e Criciúma? Ou compravam na Sociedade União Colonial?

Nas comunidades citadas, desde a década de 1930 havia vendas, igreja, escolas muito bem estruturadas, pode-se afirmar que, nesse período, em várias destas comunidades, residiam muito mais moradores do que atualmente. Pode-se afirmar também que, até a emancipação de Forquilhinha, essas comunidades estabeleciam relação socioeconômica muito maior com outras praças e municípios do que com o núcleo central de Forquilhinha. Isso não quer dizer que os colonos não comprassem ou vendessem seus produtos também na Sociedade União Colo- nial. Certamente os valores das mercadorias eram determinantes nas negociações, mas também as estradas e os preconceitos étnicos influenciavam nas atividades comerciais.

\section{$4 \mathrm{O}$ crescimento da indústria em Forquilhinha - 1959-1989}

Para compreender esse contexto, é necessário ter clareza das transformações que vinham se processando no Brasil durante a década 1950. Foi nesse período que efetivamente o Brasil experimentou a sua industrialização, mais precisamente durante o governo de Juscelino Kubitschek (1956-1960), e, com a implementação do Plano de Metas, a economia brasileira chegou a crescer $8 \%$ ao ano (SKIDMORE, 2000). Os ventos dessas mudanças certamente chegaram a Forquilhinha.

Além dessas transformações que vinham se processando em âmbito nacional, no sul catarinense anteriormente a este processo, durante a década de 1940 vivia o boom da mineração. Por ocasião da Segunda Guerra Mundial, o governo brasileiro passou a incentivar e subsidiar o consumo do carvão nacional produzido nesse período, especialmente em Criciúma. A exploração do carvão mineral veio mudar significativamente a economia da região, a população de Criciúma praticamente dobrou entre 1940 e 1950 . Ao longo das décadas de 1950 e 1960, a economia da região foi se diversificando, varias indústrias foram sendo criadas, as cerâmicas, o vestuário e o calçado ${ }^{4}$. O sul catarinense foi deixando de ser uma região estritamente agrícola. Em Forquilhinha, o leite que era destinado para a queijaria passou a ser vendido em Criciúma. “Essa fábrica de laticínios teve êxito durante trinta anos quando, com o crescimento da cidade de Criciúma, o leite não supria mais as necessidades exigidas pelas instalações e encerrou suas portas para essa atividade" (ARNS, 2003, p. 252).

Como Forquilhinha não estava isolada, os ventos dessas mudanças se fizeram sentir

\footnotetext{
${ }^{4}$ Sobre as transformações que se processaram no sul catarinense entre as décadas de 1940 a 1980 ver: GOULARTI FILHO, Alcides (Org.). Memória e cultura do carvão em Santa Catarina. Florianópolis, SC: Cidade Futura, 2004. GOULARTI FILHO, Alcides. Formação econômica de Santa Catarina. Florianópolis, SC: Cidade Futura, 2002.
} 
também na comunidade. Forquilhinha foi perdendo a característica de núcleo colonial, mas continuou a explorar as atividades vinculadas à agricultura, pecuária e suinocultura. Destacam-se, no período, a criação da Cooperativa de Eletrificação Rural em 1959, ano em que Forquilhinha foi transformada em Distrito e era instalada a Intendência, expansão da produção do arroz com instalação de indústria para sua comercialização em 1962; a fundação do Frigorífico Sul Catarinense S.A. (FRISULCA) em 1963; criação da Cooperativa Agropecuária em 1965 e, no final da década de 1960, o Grupo Maximiliano Gaidzinski assumiu o FRISULCA.

A criação do Distrito, o fechamento da Sociedade União Colonial S.A ${ }^{5}$, em 1966 (Sociedade que vinha passando por dificuldades desde o final dos anos de 1950, pois teve que vender vários imóveis para poder se manter) e a constituição de cooperativas e empresas foram fundamentais para Forquilhinha perder sua condição de núcleo colonial muito fechado e dinamizar sua economia. Basta dizer que esses novos empreendimentos não eram de exclusividade dos descendentes de imigrantes alemães. Como exemplo disso, a empresa de comercialização de arroz era de um descendente de italiano, a direção do FRISULCA era composta por descendentes de alemães, italianos e lusos e havia acionistas provenientes de Criciúma, Siderópolis, Tubarão e até de Curitiba. Esses empreendimentos contribuíram também para dar os primeiros passos na integração das várias comunidades ao núcleo central.

Posto isso, faz-se uma breve descrição desses empreendimentos que contribuíram para a dinamização da economia de Forquilhinha.

\footnotetext{
${ }^{5}$ A historiografia local procura explicar que o fechamento da Sociedade União Colonial S.A deveu-se pela alta da inflação. Infere-se que seu fechamento deveu-se muito mais pelo novo contexto sócio econômico das décadas de 1950 e 1960. Pode-se dizer que a estrutura de organização da Sociedade estava muito arcaica para enfrentar os novos tempos. Certamente os agricultores nos anos 60 já não queriam ficar presos a obrigatoriedade de vender e comprar produtos na Sociedade. Outros estabelecimentos comerciais foram surgindo como, por exemplo, o de Luis Tiscoski que passou a concorrer com a sociedade. Sobre isso ver: TISCOSKI, Adolfo. Uma história de imigrantes. Curitiba, PR: Gráfica Vicentina, 1994, p. 64.
}

\section{A Cooperativa de Eletrificação Rural}

Em Forquilhinha desde o final do século XIX, as habitações dos luso-brasileiros, italianos, alemães poloneses e russos eram iluminadas por lampiões a querosene ou lampiões Aladim (lamparina). Essa forma de energia soltava muita fumaça escurecendo o teto, as paredes das casas e deixava as narinas enfumaçadas. Posteriormente alguns colonos passaram a utilizar o liquinho. $\mathrm{Na}$ década de 1940, a Sociedade União Colonial e alguns colonos e comerciantes se associaram e instalaram um gerador de eletricidade movido à gasolina que atendia as instalações da sociedade,

A Cooperativa de Eletrificação Rural de Forquilhinha foi criada em 1959, foi fundamental para sua criação a força política do sul catarinense nessa época; o Governador Heriberto Hülse era da região, seu filho José era presidente da C.E.E. e Forquilhinha gozava de muito prestígio político, pois havia elegido três vereadores em 1955, Paulo Preis havia sido prefeito e era deputado estadual. Um ano antes da criação da Cooperativa, uma comitiva de Forquilhenses foi recebida pelo governador Heriberto Hülse, entre eles estavam os vereadores Adolfo Back e Aloísius Back; participaram também Fridolino Steiner, Fidelis Back e Valdomiro Michels, esses pleitearam ao governador que o estado levasse energia elétrica para Forquilhinha. O governador atendeu ao pedido mandando estender uma rede para eletrificação de Forquilhinha (DAROS, 2009, p. 120). Essa rede deveria ser entregue para uma instituição que a administraria. Assim, em 27 de janeiro de 1959, o governo enviou para Forquilhinha técnicos e um estatuto já preparado e, em reunião realizada no salão de festas da Sociedade União Colonial, "nós fundamos a Cooperativa com sessenta associados. Eu não tinha energia ainda, porque morava lá embaixo. Recebi energia no dia 30 de outubro de $1960^{\prime \prime}$.

$\mathrm{Na}$ reunião que criou a Cooperativa, foi também realizada a eleição para escolher os membros dos Conselhos de administração fiscal e os suplentes. Foram eleitos para

\footnotetext{
${ }^{6}$ Fridolino Steiner entrevistado por DAROS, Jorge. Meio século de história: 50 anos COOPERA, 1959-2009. Forquilhinha: COOPERA, 2009, p. 120.
} 
presidente: Alfredo Michels, Diretor-Gerente: Fidelis Back, Secretário: Alvin Kurtz, Conselheiros: Alfredo Arns e Apolinário Tiscoski (Ata de criação da Cooperativa de Eletrificação Rural de Forquilhinha, 1959). Em 1962 uma nova diretoria assumiu a Cooperativa. Na presidência: Ari Osvaldo da Silveira, Vice-presidente: Dionísio Triches, Gerente: Fridolino Steiner e Secretário: Guérion Steiner. Observa-se aqui a presença de um lusobrasileiro e descendente de italiano na direção da Cooperativa.

Com o passar dos anos, a Cooperativa foi levando energia para todas as comunidades de Forquilhinha. O senhor Fridolino Steiner, que por 21 anos foi gerente até 1989, lembra as dificuldades para levar a energia para as comunidades nos primeiros tempos da Cooperativa:

Nós partimos do nada. Ganhamos alguma coisa, o resto foi dado pelos colonos. $\mathrm{Na}$ região de Sangão, tinha eucalipto de qualidade. Os Borsatto, Casagrande. Os colonos, poucos, que podiam ajudar pagavam em serviço e quem não podia ajudar pagava em dinheiro. $\mathrm{O}$ governo mandou os fios, os isoladores, transformadores, o resto era tudo por nossa conta. [...] Em 1959 construímos a Linha Eyng. Eram colonos, um melhor do que o outro. Depois tinha a linha Santa Rosa onde morava o Augusto Vitali, que tinha engenho de arroz. Conseguiu material do Estado e construímos, a partir da Linha Eyng, pelo meio do mato, a linha de Santa Rosa. Instalamos lá dez casas. Saí da roça para ir lá construir essa rede. Um dia por semana. Ia de bicicleta. Minha família cuidava da estufa. [...] Em 1961, veio o material para construir a rede São Roque - Sangão. Aí veio o montador do Estado que fez essa rede, e eu peguei de Forquilhinha a São Roque com os colonos. Quando nós terminamos, os outros estavam ainda pela metade. [...] tivemos ajuda do Afonso Forgiarini, Romualdo Forgiarini, dos Ronchi, era gente de pegar mesmo ${ }^{7}$.

Quando da sua fundação em 1959, recebeu o nome de Cooperativa de eletrificação Rural de Forquilhinha (CERFOL) e, a partir de 1985, mudou sua nomenclatura passando a se chamar Cooperativa Mista Pioneira Ltda.

\footnotetext{
${ }^{7}$ Fridolino Steiner entrevistado por DAROS, Jorge. Meio século de história: 50 anos COOPERA, 1959-2009. Forquilhinha: COOPERA, 2009, p. 120-121.
}

(COOPERA). Essa mudança ocorreu porque a Cooperativa passou a desenvolver também atividades do setor agropecuário. O setor agropecuário descentralizou suas atividades em cinco unidades: 1) Sistema de irrigação e drenagem (Pró-Várzeas); 2) Sistema de secagem, armazenagem e comercialização de grãos; 3) Comércio de Insumos agropecuários; 4) Programa de inseminação artificial; 5) Coleta de leite (Jornal da Manhã, 31 de dezembro de 1990).

Em 2003, o setor agropecuário e o setor de distribuição de energia foram separados, nascia a COOPERNOVA desenvolvendo as atividades do setor agropecuário. E a COOPERA que permaneceu com a mesma nomenclatura passou a atuar somente na distribuição de energia. Somente em 2006, após definição em Assembleia Geral, seu nome passou a ser Cooperativa Pioneira de Eletrificação (COOPERA).

Durante seus mais de cinquenta anos, a Cooperativa foi administrada por Alfredo Michels, Ari Osvaldo da Silveira, Augusto Vitali, Mário Tiscoski, Bruno Back e Carlos Alberto Arns; passou por algumas dificuldades chegou a ter uma dívida de cerca de 17 milhões no final dos anos de 1990, mas conseguiu se recuperar a partir da medida tomada pelos gestores de transferir a cobrança da energia dos associados para o Banco (entrevista com Mário Westrup, em 18 de janeiro de 2012). Configurou-se em uma instituição importantíssima para o desenvolvimento da economia do Distrito e posteriormente município de Forquilhinha.

\section{O crescimento da produção e comerciali- zação do arroz}

A agricultura foi e ainda é uma das principais atividades em importância para a economia do município de Forquilhinha. Milho, feijão, batata, fumo e arroz eram produzidos pelos colonos para o consumo e comércio. Desses produtos, o arroz foi conseguindo um amplo mercado consumidor, e sua produção foi sendo ampliada já na década de 1940.

Mas foi na década de 1960 que o arroz teve uma maior expansão de sua produção e comercialização. Em 1962, Antonio Aléssio montou uma indústria moderna para beneficiamento de arroz contribuindo para 
a ampliação das áreas de plantio de arroz em Forquilhinha. Por essa época já havia alguns engenhos de arroz nas comunidades de Forquilhinha, como por exemplo, o de Augusto Vitali, em Santa Rosa.

Nas décadas seguintes, a produção de arroz foi crescendo, novas técnicas de plantio e maquinário moderno foram sendo incorporadas, além da criação de empresas de grande porte que comercializavam. Em 1990, um ano após a emancipação, foram produzidas no município 14.400 toneladas de arroz, e essa produção foi se multiplicando nos anos seguintes (Censo agropecuário, 2010)

\section{Da criação do FRISULCA a sua incorpo- ração pelo Grupo Gaidizinski}

Fundado em 1963, o Frigorífico Sul Catarinense S.A. (FRISULCA) visava à industrialização de produtos alimentícios derivados de animais suínos e bovinos. Dessa sociedade, participaram acionistas de Forquilhinha, Criciúma, Siderópolis, Tubarão e de Curitiba. Inicialmente foram realizados estudos de viabilidade do empreendimento, pois a sua concretização demandava vultosas somas de recursos para construção de uma estrutura que fosse lucrativa. O empreendimento envolveria todos os municípios do sul catarinense que poderiam fornecer os animais. Os estudos apontaram para a grande viabilidade do empreendimento e escolhiam Forquilhinha para localização do FRISULCA. A diretoria foi composta por empresários e lideranças de vários municípios e de várias etnias. A sociedade anônima iniciou com um capital de 10 milhões de cruzeiros velhos.

Entre 1963 a 1966 foi adquirido terreno e foram sendo realizadas as construções e instalados os equipamentos para o funcionamento do FRISULCA. Foram perfurados dois poços semiartesianos com 80 metros, para garantir a água para a indústria.

Em Assembleia Geral realizada em 19 de setembro de 1964, foi aumentado o capital da empresa para 20 milhões de cruzeiros com participação de representantes de quase todos os municípios do sul Catarinense. Em 30 de abril de 1966, era realizada Assembleia Geral Extraordinária a fim de aumentar o capital da empresa num montante de 500 milhões de cruzeiros, pois este vinha se desvalorizando pela inflação (BACK, 1995, p. 70-72).
OFRISULCA entrou em funcionamento no ano de 1966, abatendo suínos e bovinos, mas a falta de capital de giro e a inflação que corroeu o capital da empresa impediram que ela continuasse em funcionamento sendo vendida para o Grupo Maximiliano Gaidizinski de Criciúma. Este recuperou a empresa colocando-a em pleno funcionamento. Posteriormente a empresa investiu em maquinário automatizado e, na década de 1980, exportava seus produtos congelados para os grandes centros do país e também para outros países (GATELLI, 1987, p. 48).

É imperativo fazer uma reflexão sobre as explicações apontadas para as dificuldades enfrentadas pelo FRISULCA (inflação e falta de capital de giro) que levaram à sua venda. Como um empreendimento de tal porte, em que havia sido feito um estudo de viabilidade econômica, criou uma estrutura de frigorífico moderna e não levou em consideração a necessidade de capital de giro e a própria inflação? Em 1963 quando da criação do FRISULCA, o país já estava com inflação alta e vivenciava um dos períodos mais turbulentos de sua história: greves em todo país, mobilizações contra e a favor do governo do presidente João Goulart e o golpe militar em março de 1964. (REGO; MARQUES, 2005). Em 1966, quando o FRISULCA começou suas atividades, a inflação do país não era maior do que em $1963^{8}$. Infere-se que as explicações das dificuldades do FRISULCA não são suficientes para explicar a sua venda para o Grupo Maximiliano Gaidizinski.

\section{Economia de Forquilhinha impulsionada pela cerâmica e mineração}

A exploração do carvão mineral teve início no território de Forquilhinha na década de 1960 com a Carbonífera Criciúma. Em 1982, a Carbonífera Criciúma começou a operar no Bairro Vila Franca. Posteriormente, a Cooperminas iniciava suas atividades no Bairro Santa Líbera. Em 2002, a Mineração Caravagio deu início às suas atividades no Bairro Ouro Negro (GLUCK, 2006, p. 49). Se, por um lado, a mineração contribuiu e vem contribuindo

\footnotetext{
${ }^{8}$ Sobre a taxa de inflação brasileira da década de 1960 ver: Revista de Economia Política, v. 5, n. 4, p. 15-30, out./ dez. 1985.
} 
com empregos e impostos para o município, por outro, vem trazendo o problema da poluição ambiental.

Em 1971, a família Forgiarini fundou a cerâmica Solar Ltda. Segundo Romualdo Forgiarini, seu pai, José Forgiarini, chegou a Forquilhinha por volta de 1911, tinha um engenho de farinha e criava porco, que era vendido para fazer banha. Relata que, em 1965, montou um armazém de secos e molhados, comprou um caminhão que fazia serviços nas minas, e, em 1971, comprou a cerâmica do senhor Dionísio Triches (entrevista com Romualdo Forgiarini, 2011). O início da cerâmica foi lembrado também por José Forgiarini:

Não tinha muito comércio de tijolo quando nos compramos em 71. Levamos sorte, abriu a BR - 101 e os produtos passaram a ser levados para o Rio Grande do Sul. Fomos ampliando, em 1976 começamos a produzir pisos rústicos, colonial, conhecido como lajota, e a gente abriu para São Paulo, Paraná, Mato Grosso, mandamos para o Paraguai, Uruguai, Argentina e cresceu bastante. Mas hoje passou aquela fase. (Entrevista com Romualdo Forgiarini, 2011).

Na década de 1970, ocorreu a expansão do setor cerâmico devido ao crescimento acelerado da construção civil. Haviam sido criados na década anterior o BNH (Banco Nacional de Habitação) e o SFH (Sistema Nacional de Habitação) em 1964, que fomentavam a construção civil, mas colocados em prática somente a partir de 1968 (GOULARTI FILHO, 2002, p. 238-239). A cerâmica Solar produzia tijolos e "lajotão colonial" produto muito apreciado nas décadas de 1970, 80 e 90. Inicialmente a produção da empresa era vendida somente em Santa Catarina, posteriormente a produção passou a ser comercializada em outros estados atingindo todo o mercado nacional. O "lajotão colonial" foi comercializado também no mercado externo, sendo exportado para os países do Mercosul e também para a África do Sul.

Em 2003, a empresa fez a opção por produzir somente telhas do tipo portuguesa e romana, produto que vinha aumentando o consumo no mercado nacional.

A criação do distrito e todos os empreendimentos descritos contribuíram para a dinamização da economia e deram os primeiros passos para uma integração das várias comunidades com Forquilhinha, pois, até a década de 1950, essas comunidades estabeleciam relações socioeconômicas com outros municípios ou outras comunidades como, por exemplo, Maracajá, Meleiro e Nova Veneza, e muito pouco com o centro.

\section{A emancipação e a integração socioeco- nômica de Forquilhinha: 1989-2011}

Todos os empreendimentos já citados anteriormente e a criação do distrito foram significativos para a dinamização da economia e contribuíram para uma integração das várias comunidades de Forquilhinha a partir da década de 1960, mas foi a emancipação política que integrou Forquilhinha contribuindo decisivamente para o seu desenvolvimento socioeconômico.

A partir da emancipação o comércio e a indústria foram florescendo rapidamente, os vários setores já implantados no município ampliaram suas instalações, a presença do poder público com as várias secretarias, saúde, educação, agricultura aproximaram as comunidades do centro. Comunidades que outrora estabeleciam relações socioeconômicas com outros municípios, Meleiro, Maracajá e Nova Veneza, com a emancipação voltaram-se para Forquilhinha.

O crescimento da indústria, do comércio, as agências bancárias, as atividades ligadas ao setor público possibilitaram o aumento dos postos de trabalho, o processo de urbanização, a crescente migração e o aumento da população do município. A urbanização e o crescimento da população ficam evidenciados nos censos demográficos apresentados pelo IBGE entre 1970 a 2010. 


\begin{tabular}{|c|c|c|c|c|c|}
\hline Ano/Década & População & Homens & Mulheres & $\begin{array}{c}\text { População } \\
\text { Urbana }\end{array}$ & $\begin{array}{c}\text { População } \\
\text { Rural }\end{array}$ \\
\hline 1970 & 7.094 & 3.635 & 3.459 & 479 & 6.615 \\
\hline 1980 & 10.860 & 5.515 & 5.345 & 2.689 & 8.171 \\
\hline 1991 & 14.058 & 7.174 & 6.884 & 4.397 & 9.661 \\
\hline 2000 & 18.349 & 9.293 & 9.056 & 14.557 & 3.792 \\
\hline 2010 & 22.548 & 11.309 & 11.239 & 18.426 & 4.122 \\
\hline
\end{tabular}

Quadro 1 - População de Forquilhinha 1970-2010

Fonte: Censo demográfico IBGE

A urbanização fica evidenciada também quando se observa o grande crescimento vertiginoso dos bairros constituídos próximos ao centro de Forquilhinha, como por exemplo: Vila Lourdes, Clarissas, Ouro Negro e Nova York. Nesses bairros, é significativa a presença de população migrante, atraída pela oferta de trabalho que o município possibilita. São trabalhadores provenientes dos municípios do Sul Catarinense e muitos de outros estados.

Em relação à indústria, foi notável o crescimento da empresa Agroeliane S/A que em 1990, empregava 1.500 trabalhadores diretos e produzia "mensalmente 1.800 toneladas de carne de frango e 1.250 toneladas de carne suína, colocando $40 \%$ no mercado externo" (Jornal da Manhã, 31 de dezembro de 1990). Além disso, a empresa era produtora de rações, absorvia toda a colheita de milho da região e sustentava através das suas linhas de produção de carne de frango e de suínos, uma significativa rede de criadores integrados (Jornal da Manhã, 31 de dezembro de 1990).

Em 1995, a Agroeliane foi adquirida pelo grupo Seara alimentos, que concentrou suas atividades em Forquilhinha somente na produção de frangos, a unidade que fazia o abate de suínos (FRISULCA) foi fechada e 400 trabalhadores foram demitidos. Até 1995 os trabalhadores desta empresa eram na sua maioria de Forquilhinha. A empresa estabelecia uma boa relação com a comunidade. Havia uma identidade da comunidade com a empresa. Os novos proprietários da empresa se fecharam para a comunidade e esta relação de identidade comunidade/empresa foi se perdendo'.

Em 2005, passou para o controle do grupo Cargil, um dos maiores produtores mundial de alimentos e, em 2009, a Seara alimentos foi adquirida pelo Marfrig Group que empregava em 2011 mais de 2.000 trabalhadores em Forquilhinha, sendo que mais de $65 \%$ desses trabalhadores eram do sexo feminino. O grupo Cargil procurou restabelecer uma boa relação com a sociedade de Forquilhinha, prática que vem sendo ampliada pelo Marfrig Group.

Mesmo com a urbanização e o crescimento da indústria e do comércio em Forquilhinha, a produção da área rural continuou a ter relevância na economia do município, em especial o arroz.

\footnotetext{
${ }^{9}$ Segundo Célio Alves Elias o grupo Gaidizinski vendeu a Agroeliane para salvar a cerâmica Eliane que estava passando por uma crise. A marca Seara esteve sobre o controle da Ceval alimentos que pertencia ao grupo Hering e posteriormente vendido para a empresa americana Bung. Estas empresas se afastaram da sociedade forquilhense que quando pertencia a Agroeliane eram sempre recebidas. Varias entidades do município quando organizavam um evento procuravam a empresa e eram atendidas.
} 


\begin{tabular}{|c|c|c|c|c|c|c|c|c|c|c|c|c|c|c|c|c|c|c|c|c|c|}
\hline 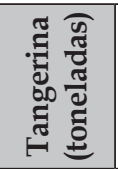 & ' & ' & ' & ' & & & 초 & 1 & ' & ' & & స్ & 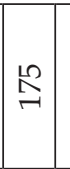 & ষ্ণি & ঃ্ৰ: & I্ㄱㄱ웍 & ৪ & ' & ' & & $\begin{array}{l}\text { I্ } \\
\text { î }\end{array}$ \\
\hline 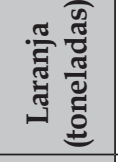 & ' & ' & 1 & ¿ & $\stackrel{\mathscr{I}}{\stackrel{I}{*}}$ & 韋 & ని & ৪ু & \& & \& & ঃু & $\vec{\sim}$ & ' & 1 & ' & ' & ' & ' & ' & ' & 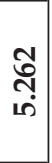 \\
\hline 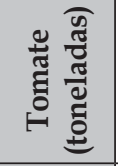 & 1 & जิ & $\stackrel{\overbrace{}}{\sim}$ & 总 & సి & ลิ & in & 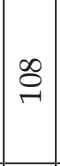 & q & $\stackrel{10}{\infty}$ & $\stackrel{\stackrel{2}{N}}{\mathrm{~N}}$ & $\stackrel{\circ}{m}$ & 品 & 잉 & $\stackrel{100}{\circ}$ & ' & ' & ' & ' & ' & ت্ \\
\hline 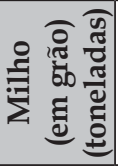 & 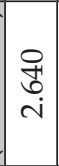 & 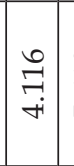 & $\begin{array}{l}\stackrel{9}{\overrightarrow{0}} \\
\stackrel{\circ}{\circ}\end{array}$ & \begin{tabular}{|l|} 
\\
$+\infty$ \\
+ \\
+ \\
+
\end{tabular} & $\mid \begin{array}{l}0 \\
0 \\
\infty \\
c \\
0\end{array}$ & $\begin{array}{l}0 \\
\infty \\
\infty \\
\infty \\
0\end{array}$ & $\begin{array}{c}8 \\
0 \\
0 \\
\dot{c}\end{array}$ & 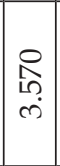 & 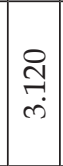 & 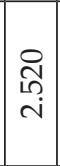 & $\left|\begin{array}{c}0 \\
i \\
i \\
i\end{array}\right|$ & 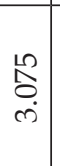 & 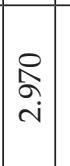 & 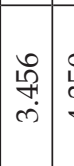 & \begin{tabular}{c|c}
$\stackrel{8}{0}$ \\
$m$ \\
$\stackrel{+}{*}$
\end{tabular} & 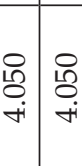 & $\left|\begin{array}{l}\stackrel{P}{f} \\
\underset{f}{+}\end{array}\right|$ & $\begin{array}{l}\mathbb{D} \\
\mathbb{1} \\
i \\
i n\end{array}$ & 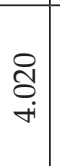 & $\begin{array}{l}\vec{a} \\
\text { ஸे }\end{array}$ & $\begin{array}{c}7 \\
7 \\
10 \\
00 \\
10\end{array}$ \\
\hline 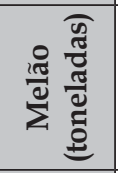 & 1 & 1 & $\infty$ & $\triangle$ & $\curvearrowright$ & $\curvearrowright$ & $\infty$ & 이 & ' & 0 & 0 & ' & 1 & ' & ' & ' & ' & ' & ' & ' & से \\
\hline 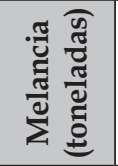 & 1 & $\cong$ & $\curvearrowright$ & $\stackrel{\stackrel{2}{\sim}}{\sim}$ & $\stackrel{20}{\sim}$ & $\approx$ & $\approx$ & $\stackrel{10}{\sim}$ & $\stackrel{\stackrel{2}{N}}{\circ}$ & $\stackrel{\stackrel{2}{\sim}}{\sim}$ & $\stackrel{\stackrel{\sim}{N}}{ }$ & ષ્సి & ' & ' & ' & ' & ' & ' & ' & ' & 点 \\
\hline 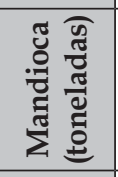 & 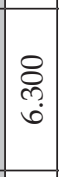 & 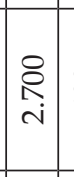 & 8 & $\left|\begin{array}{l}8 \\
\vdots \\
⿱ 亠 乂 \\
\text { in }\end{array}\right|$ & 辛 & 辛 & $\begin{array}{l}8 \\
\stackrel{0}{2} \\
\text { in }\end{array}$ & 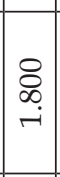 & 胥 & $\mid \begin{array}{c}\stackrel{8}{8} \\
0 \\
- \\
-1\end{array}$ & ঃ & ৪ & 윰 & 윤 & ৪ু ঃ & ৪ু ৪ু & ৪ & ৪ి & ৪ & ৪ & 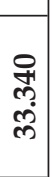 \\
\hline 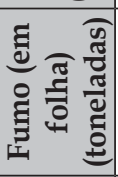 & 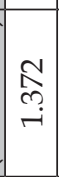 & $\stackrel{2}{2}$ & $\begin{array}{l}\mathcal{Z} \\
\stackrel{\sim}{-}\end{array}$ & 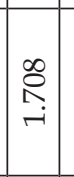 & 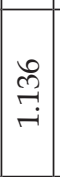 & $\begin{array}{l}\infty \\
\infty \\
\infty\end{array}$ & 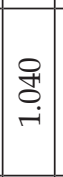 & \begin{tabular}{|l|}
$\vec{\infty}$ \\
$\stackrel{\infty}{\leftrightarrow}$ \\
\end{tabular} & $\mid \begin{array}{c}\text { 암 } \\
\stackrel{-}{-}\end{array}$ & 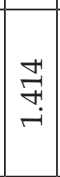 & สู & $\stackrel{\stackrel{\llcorner}{\sim}}{\stackrel{\sim}{\sim}}$ & $\mid \begin{array}{c}0 \\
0 \\
\\
-i\end{array}$ & 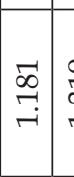 & 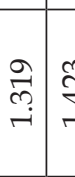 & 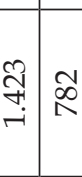 & $\widetilde{\infty}$ & \%̊ & 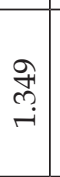 & $\underset{\overbrace{}}{\stackrel{7}{-}}$ & 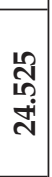 \\
\hline 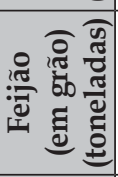 & 边 & 状 & 迎 & F & స̊ & $\stackrel{2}{i n}$ & શิ & $\underset{⿱ ㇒}{\mathbb{N}}$ & ஜ & 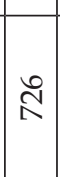 & $\mathbb{\infty}$ & $\mathbb{F}$ & \begin{tabular}{l|}
20 \\
$m$
\end{tabular} & \begin{tabular}{|l|l}
$\mathscr{2}$ \\
$\stackrel{9}{q}$ \\
\end{tabular} & તેస & \begin{tabular}{c|c}
$\mathbb{N}$ & \multirow{b}{c}{} \\
\end{tabular} & مิ & 芯 & శ్ర & $\stackrel{\infty}{\infty}$ & $\begin{array}{l}\text { त̂ } \\
\text { f! } \\
\text { ○ी }\end{array}$ \\
\hline 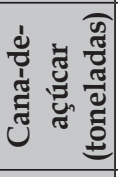 & & 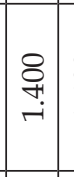 & 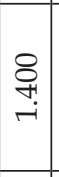 & $\left|\begin{array}{l}8 \\
\vdots \\
\hdashline \\
-i\end{array}\right|$ & 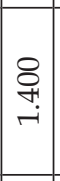 & 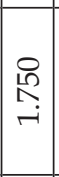 & 옷 & 员 & 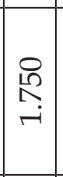 & 总 & 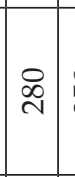 & 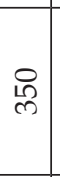 & 只 & 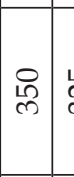 & \begin{tabular}{l|l}
$\stackrel{L}{L}$ \\
$\stackrel{2}{\sigma}$
\end{tabular} & \begin{tabular}{l|l}
$\stackrel{2}{2}$ \\
\end{tabular} & $\stackrel{\stackrel{\sim}{N}}{\widetilde{N}}$ & $\begin{array}{l}\stackrel{2}{n} \\
\tilde{n}\end{array}$ & ิㅡ & 8 & 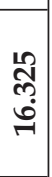 \\
\hline 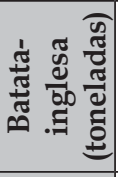 & 号 & $\begin{array}{l}\infty \\
\sim \\
\sim\end{array}$ & $\stackrel{\llcorner}{\stackrel{\llcorner}{N}}$ & 鬲 & \begin{tabular}{|l|}
$\infty$ \\
$\infty$ \\
$\infty$
\end{tabular} & $\begin{array}{c}\mathbb{R} \\
\text { m }\end{array}$ & $\begin{array}{l}8 \\
\text { D }\end{array}$ & \&্+ & $\frac{10}{\infty}$ & 8 & 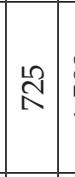 & & டిర్ & 8 & \begin{tabular}{l|l}
1 & 1 \\
$\infty$ & $\alpha$ \\
$\infty$ & $\alpha$
\end{tabular} & \begin{tabular}{l|l}
$\infty$ & 8 \\
$\infty$ & 8
\end{tabular} & $\begin{array}{l}8 \\
\varnothing\end{array}$ & 㿣 & 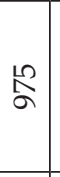 & 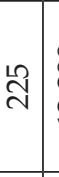 & $\begin{array}{l}\text { సે } \\
\text { త్ }\end{array}$ \\
\hline 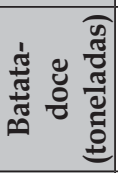 & & ' & 1 & ' & ' & ' & ' & 1 & 1 & 1 & ' & ' & ' & $\infty$ & $\infty$ & $\bowtie \infty$ & $\infty$ & $\infty$ & ' & 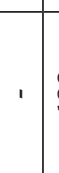 & $\underset{\infty}{\infty}$ \\
\hline 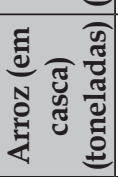 & 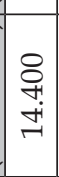 & 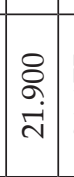 & 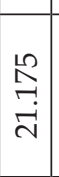 & 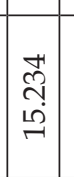 & 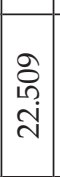 & 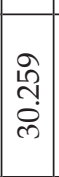 & $\begin{array}{c}8 \\
8 \\
\vdots \\
\stackrel{1}{n}\end{array}$ & $\begin{array}{l}8 \\
\stackrel{8}{1} \\
\stackrel{1}{a}\end{array}$ & $\begin{array}{c}8 \\
\Xi \\
\infty \\
\infty \\
\infty\end{array}$ & \begin{tabular}{l}
8 \\
8 \\
$\infty$ \\
\hdashline \\
\hdashline \\
\end{tabular} & \begin{tabular}{|l|}
0 \\
0 \\
$\infty$ \\
$\infty$ \\
$\infty$ \\
$\infty$
\end{tabular} & 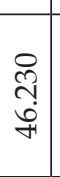 & 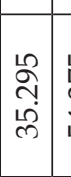 & 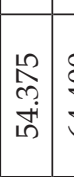 & 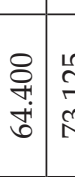 & 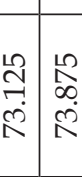 & 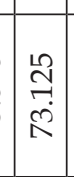 & 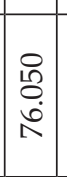 & 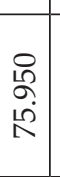 & $\begin{array}{l}R \\
\stackrel{R}{a} \\
\stackrel{1}{8}\end{array}$ & $\begin{array}{l}\text { 今్ } \\
\text { مิ } \\
\text { సू }\end{array}$ \\
\hline 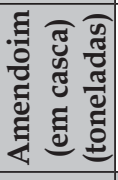 & & 完 & , & ' & ' & ' & $-r$ & - & -1 & ' & ' & ' & ' & 1 & ' & I & ' & 1 & ' & ' & $m$ \\
\hline$\stackrel{\xi}{\xi}$ & ৪ু & $\bar{\sigma}$ & જે & ळ̆ & 苟 & そ2 & よ̊ & बे & 吕 & 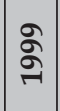 & ఫેં & ธิ่ & ઠิे & ڤ్రి & ఫ্ণ & 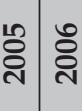 & ठ্ণે & ڤે̀े & ڤ્તે & 올 & 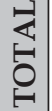 \\
\hline
\end{tabular}


Dos quatorze produtos do gênero agrícola que estão no quadro acima, observa-se que a produção de arroz foi a que mais cresceu no ano de 1990; foram produzidas 14.400 toneladas, produção que foi crescendo nos anos subsequentes chegando ao auge em 2008 com 76.050 toneladas.

Quanto à produção de batata inglesa, cana-de-açúcar, feijão, fumo, mandioca e milho, estes foram sendo produzidos anualmente durante todo o período de 1990 a 2010, mas, com uma produção que oscilava de ano para ano diferenciando-se do arroz cuja produção foi sempre crescente. Em relação aos demais produtos, amendoim, batata doce, melancia, melão, tomate, laranja e tangerina não tiveram uma sequência na sua produção, foram produzidos somente em alguns anos.

A emancipação constituiu-se em um passo relevante para a integração socioeconômica de Forquilhinha e também política, religiosa e cultural. Além da presença do poder público, nas várias comunidades, do crescimento da indústria e do comércio, do processo de urbanização e da migração foram sendo criadas associações de moradores, clubes de mães, clube de idosos contribuindo cada vez mais para integração de todas as comunidades a Forquilhinha.

A migração de trabalhadores para no município vem contribuindo para ampliar a diversidade étnica e deixar Forquilhinha muito mais plural. São luso-brasileiros, italianos, alemães, poloneses, russos, japoneses, afrodescendentes e outros grupos étnicos vivendo e construindo o município de Forquilhinha.

\section{Referências}

ARNS, Otília. Forquilhinha 1912-2002: história e resgate da memória dos nossos antepassados. Florianópolis, SC: IOESC, 2003

BACK, Adolfo. 100 anos: história de Forquilhinha. Criciúma, SC: Ed. UNESC, 1995.

DALL'ALBA, João Leonir. Histórias do grande Araranguá. Araranguá, SC: Orion, 1997.

DAROS, Jorge. Meio século de história: 50 anos COOPERA, 1959-2009. Forquilhinha, SC: COOPERA, 2009.

GATELLI, Gema. A evolução econômica de Forquilhinha. 1987. Monografia (Especialização em História) Universidade do Extremo Sul Catarinense (Unesc), Criciúma, SC.

GLUCK, Renê. Forquilhinha: linda de viver, Santa Catarina, Brasil. Forquilhinha, SC: [s.n.], 2006.

GOULARTI FILHO, Alcides (Org.). Memória e cultura do carvão em Santa Catarina. Florianópolis, SC: Cidade Futura, 2004.

GOULARTI FILHO. Alcides. Formação econômica de Santa Catarina. Florianópolis, SC: Cidade Futura, 2002.

HOBSBAWM, Eric. Era dos extremos: o breve século XX 1914 - 1991. 2. ed. São Paulo: Companhia das Letras, 1995.

MACHADO, Rosiane. A organização econômica de Forquilhinha: a Sociedade União Colonial (1935 a 1966). Criciúma, SC: Unesc, 2004.

REGO, Márcio; MARQUES, Rosa Maria. Economia brasileira. São Paulo: Saraiva, 2005.

REVISTA DE ECONOMIA POLÍTICA, v. 5, n. 4, p. 1530, out. /dez. 1985.

SILVA, Walburga Arns. Saga de uma família teuto-brasileira: Lehrer Arns, registros e vida de um professor de colônia. São Leopoldo, RS: Ed. UNISINOS, 1998.

SKIDMORE, Thomas E. Brasil: de Getúlio Vargas a Castelo Branco. São Paulo: Paz e Terra, 2000.

SOUTO, Américo A. da Costa. Evolução histórico-econômica de Santa Catarina: estudo das alterações estruturais (século XVII-1960). Florianópolis, SC: Centro de Assistência Gerencial de Santa Catarina - CEAG/SC, 1980.

TISCOSKI, Adolfo. Uma história de imigrantes. Curitiba, PR: Gráfica Vicentina, 1994.

ZANELATTO, João Henrique; OSÓRIO, Paulo Sérgio. Forquilhinha: do presente para o passado, outras memórias uma nova história. Forquilhinha, SC: Ed. UNESC, 2012. 